and such a discussion, though independent of optics, would be certain to have important applications in it, because its results would often still apply when translated into language of the electro-magnetic theory. The mathematical investigation of vibrations might be made more clear and definite when it is freed from the necessity of adapting itself to experimental verification.

Chapter xviii. is a useful one, dealing with "theories based on the mutual reaction between ether and matter," but we might have wished for a more satisfactory introduction to the electro-magnetic theory that is given in the last two chapters. The way in which the subject is approached may illustrate some of the remarks made in the beginning of this review. There is no doubt a very serious difficulty in explaining the fundamental notions underlying the theory, and Mr. Basset, instead of making an attempt to help the student over the difficulty, suddenly plunges into a series of equations, referring us to Maxwell's book for an explanation even of his symbols.

We have perhaps given an inadequate idea of the contents of Mr. Basset's book, which no doubt lends itself to criticism from the physicist's point of view, but which nevertheless fills a gap and possesses merits which will render it of great value to the student of optics.

ARTHUR SCHUSTER.

\section{THE APODIDEE.}

The Apodidee: a Morphological Study. By H. M. Bernard, M.A. Cantab. (London: Macmillan, i 892.)

THE title of this little book is misleading. It is not a treatise on the Apodidæ, but a statement of the author's speculations on the relations of the Phyllopodous Crustacea and Branchiate Arachnida to the Chætopod Worms. The new observations recorded are few, and the most important, that as to the presumed hermaphroditism of Apus cancriformis, quite insufficiently set forth, and, so far as can be judged from the author's meagre statement, erroneous.

Mr. Bernard appears to be completely misinformed as to current views on the relationships of Apus to other Crustacea, and of that group, through it, to the parapodiate worms. Apparently he addresses himself to a lay audience, and poses, to start with, as the discoverer of a new and unsuspected agreement between the lower Crustacea and the Chætopoda. This may serve to excite the interest of uninstructed readers, but the zoologist knows that such pretensions are due either to defective acquaintance with the subject or to a want of candour on Mr. Bernard's part. The arguments by which Mr. Bernard endeavours to support his thesis are, many of them, those which have been effectively used by his predecessors in the same cause; others are new and remarkable only for their arbitrary character and the evidence which they give of the author's boldness in writing a book on a morphological problem. $\mathrm{Mr}$. Bernard draws attention to the absence of developed articulations in the limbs of Apus as giving them a resemblance to the parapodia of Chætopoda. He states that this absence "has already been pointed out by Lankester and others, but its true significance does not seem to have been noticed." This is an incorrect alluNO. I I 86 , VOL. 46] sion to my essays on the appendages and nervous system of Apus (Q. J. Micr. Sci., 188I), and on Limulus an Arachnid (ibid.), which is the more to be regretted since they appear to have furnished Mr. Bernard with such of his theories as well as his facts as will bear examination. At p. 368 , loc. cit., my statement runs-

"I have long been of the opinion which Prof. Claus appears to hold, that the appendages of the Arthropoda are homologous (or, to use a more distinctive term, 'homogenous') with the appendages of the Chætopoda, and on this account I consider it a proper step in classification to associate the Chætopoda with the Arthropoda and Rotifera in one large phylum-the Appendiculata."

Yet Mr. Bernard comes forward to tell us that he now for the first time draws attention to the true significance of the absence of articulations in the limbs of Apus, although (as he admits) this condition was especially noted and very carefully described eleven years ago by me in the same essay in which the above paragraph as to the relationship of Arthropoda and Chrtopoda occurs. This is a sample of Mr. Bernard's method of claiming novelty for what he has to say when dealing with old materials. Frequently he asserts in. strong language novel propositions which are purely speculative and of the truth of which no evidence is adduced. There is in no part of this little book any evidence that the author has made use of living or of well-preserved material, or has had any special opportunities of studying the genera and species of Apodidx; nor does it appear that he has any experience as a zoologist which might give some weight to his fanciful conceptions. On the contrary, these crude speculations and dogmatic assertions are his first original contributions to zoological literature. I regret to be obliged to say that in my opinion (which I am called upon to express candidly in these pages) "The Apodidæ" is not a book which can be recommended either as a repository of fact or as a model of the method in which a morphological problem should be attacked.

E. RAY LANKESTER.

\section{OUR BOOK SHELF.}

Anatomy, Physiology, Morphology, and Development of the Blow-fly (Calliphora erythrocephala). Part III. By B. Thompson Lowne, F.R.C.S., F.L.S. (London: R. H. Porter, I 892.)

WE have before us another section of Mr. Lowne's work, which has grown upon the author's hands, and will form two volumes instead of the one originally intended. Part iii. is occupied with the internal anatomy of the imago, embryonic development, histology, and the development of the imago. On each of these heads a great amount of information is supplied, and the author's statements are illustrated by many figures. As to the puzzling question of the way in which the alimentary canal of the blow-fly is developed, Mr. Lowne holds an opinion which is probably shared with no second person. What Voeltzkow and Graber take to be the proctodæum, and what Korschelt and Heider believe to be the amniotic cavity, Mr. Lowne calls archenteron. He is content, as he tells us in his preface, to await the verdict of posterity on such conclusions as this. We are content to wait too. The subject is too difficult for full consideration in this place, and it would be unfair to express a strong opinion without ample discussion of the evidence. It is not unfair, we think, to characterize many of Mr. Lowne's 